\title{
Hubungan Status Gizi dengan Kelelahan Kerja Pada Pekerja Di SPBE Indramayu
}

\author{
The Relationship of the Workload and Nutritional Status with the Fatigue of Workers in Work on the SPBE \\ Indramayu
}

\section{Eka Nur Aisyah ${ }^{1}$, Sarinah Basri $K^{2}$}

\author{
${ }^{1,2}$ Program Studi Kesehatan Masyarakat Universitas Wiralodra \\ e-mail: b_sarinah@yahoo.com
}

\begin{abstract}
Abstrak
Kelelahan kerja merupakan kondisi melemahnya tenaga untuk melakukan suatu pekerjaan. Kelelahan kerja dapat menimbulkan efek yang buruk bagi kesehatan para pekerja. Kelelahan dapat disebabkan oleh beberapa faktor diantaranya beban kerja dan status gizi. Tujuan penelitian ini untuk mengetahui Hubungan Status Gizi dengan Kelelahan Kerja Pada Pekerja di SPBE Indramayu Tahun 2017".

Penelitian ini menggunakan desain cross sectional, teknik yang digunakan dalam pengambilan sampel adalah purposive sampling. Sampel dalam penelitian ini adalah pekerja bagian operator loading di SPBE Indramayu yang memenuhi kriteria inklusi, sebanyak 39 orang pekerja. Data mengenai kelelahan kerja diukur dengan menggunakan kuesioner 30-item gejala kelelahan umum IFRC. Uji statistik menggunakan uji Fisher Exact Test.

Hasil penelitian diperoleh nilai status gizi pekerja dengan $p$-value 0,005 dengan nilai Spearman Correlation $(\mathrm{SC})=$ 0,485. Maka dapat disimpulkan bahwa Ho ditolak, artinya menunjukan ada hubungan antara status gizi dengan kelelahan kerja pada pekerja di SPBE Indramayu Tahun 2017. Para pekerja sebaiknya mengonsumsi makanan yang bergizi seimbang dan memaksimalkan waktu istirahat.
\end{abstract}

Kata Kunci : status gizi, kelelahan kerja

\section{Abstract}

Job fatigue is a condition of weakening the power to do a job. Job exhaustion can have adverse effects on the health of workers. Fatigue can be caused by several factors including workload and nutritional status. The purpose of this study is to determine the relationship of nutritional status with work fatigue in workers in SPBE Indramayu 2017 ".

This study uses a cross sectional design, the technique used in sampling is purposive sampling. The sample in this study was the part of the loading operator workers in the Indramayu SPBE which met the inclusion criteria, as many as 39 workers. Data on work fatigue was measured using a 30 item IFRC general fatigue symptom questionnaire. Statistical test using the Fisher Exact Test.

The results obtained by the value of the nutritional status of workers with $p$-value 0.005 with the value of Spearman Correlation $(S C)=0.485$. So it can be concluded that $\mathrm{Ho}$ is rejected, meaning that there is a relationship between nutritional status and work fatigue in workers at Indramayu
SPBE in 2017. Workers should consume foods that are balanced and maximize resting time

Keywords: nutritional status, work fatigue

\section{Pendahuluan}

Salah satu faktor penyebab utama kecelakaan kerja yang disebabkan oleh manusia adalah stress dan kelelahan. ${ }^{1}$ Kelelahan kerja memberi kontribusi 50\% terhadap terjadinya kecelakaan kerja. Bahkan dari hasil penelitian disebutkan bahwa $80 \%$ human error, 50\% nya disebabkan oleh kelelahan kerja. $^{2}$ Kelelahan didefinisikan sebagai suatu pola yang timbul pada suatu keadaan yang secara umum terjadi pada setiap individu yang telah tidak sanggup lagi untuk melakukan aktivitasnya. ${ }^{3}$ Kelelahan adalah perasaan subyektif, tetapi berbeda dengan kelemahan dan memiliki sifat bertahap. Tidak seperti kelemahan, kelelahan dapat diatasi dengan periode istirahat. ${ }^{4}$

Terdapat lima kelompok sebab kelelahan yaitu: monotonitas/pekerjaan monoton, intentitas kerja yang terlalu besar dan durasi kerja yang terlalu lama, keadaan lingkungan seperti penerangan, getaran dan kebisingan, keadaan kejiwaan seperti tanggungjawab, kekhawatiran dan konflik, penyakit, perasaan sakit dan keadaan gizi. ${ }^{3}$ Selain penyebab tersebut, ada faktor individu yang mempengaruhi tingkat kelelahan, ${ }^{5}$ faktor individu meliputi umur, jenis kelamin, status gizi, kondisi kesehatan, kondisi psikologi dan sikap kerja.

Tenaga kerja dengan keadaan gizi yang baik akan memiliki kapasitas dan ketahanan tubuh yang lebih baik. Namun jika keadaan 
gizi buruk akan mengganggu kerja dan menurunkan efisiensi serta timbul kelelahan. ${ }^{6}$ Bila tubuh memperoleh cukup zat-zat gizi dan digunakan secara efisien akan tercapai status gizi optimal yang memungkinkan pertumbuhan fisik, perkembangan otak, kemampuan kerja dan kesehatan secara umum pada tingkat setinggi mungkin. ${ }^{7}$

Berdasarkan latar belakang diatas, maka permasalahan dalam penelitian ini adalah: Apakah ada hubungan beban kerja dan status gizi dengan kelelahan kerja pada pekerja di Stasiun Pengisian Bulk Elpiji (SPBE) Indramayu Tahun 2017

\section{Metode}

Jenis penelitian ini menggunakan desain cross sectional, penelitian ini dilaksanakan di Stasiun Pengisian Bulk Elpiji Indramayu yaitu SPBE PD. BWI dan SPBE PT. Fajar Cahaya Pantura yang mulai dilaksanakan pada bulan Mei-Juni 2017. Sampel penelitian sebanyak 39 orang responden, teknik yang digunakan dalam pengambilan sampel adalah purposive sampling dengan mengambil Karyawan SPBE yang bekerja di bagian operator loading yang burumur < 49 tahun. Data status gizi diukur dengan menggunakan timbangan dan meteran, kriteria IMT dibagi menjadi 2 yaitu kriteria IMT tidak normal : $\leq 18,4$ dan $\geq 25$, sedangkan untuk kriteria normal: 18,5-24,9. Data mengenai kelelahan kerja diukur dengan menggunakan kuesioner 30-item gejala kelelahan umum IFRC dan kriteria untuk pengukuran kelelahan dibagi menjadi 2 yaitu kelelahan rendah : 30-75 dan kelelahan tinggi : 76-120.

\section{Hasil}

\section{Gambaran Umum Lokasi Penelitian}

SPBE adalah singkatan dari Stasiun Pengisian Bulk Elpiji, sarana khusus dari PT. Pertamina (Persero) untuk penyaluran dan pelayanan LPG bagi masyarakat umum yang semula pengguna minyak tanah dan beralih sebagai pengguna LPG melalui agen LPG $3 \mathrm{~kg}$ eks agen minyak tanah, di Indramayu program konversi dari minyak tanah ke LPG telah dilaksanakan dari tahun 2008.

Saat ini Indramayu memiliki lima titik supply untuk pengisian LPG kemasan 3 kilogram, yakni FD Depot Balongan, SPBE PT Poly Jasa di Kecamatan Krangkeng, SPBE PT Rahayu Surya Gemilang di Kecamatan Sukagumiwang, SPBE PT Fajar Cahaya Pantura di Kecamatan Widasari, serta SPBE PD. Bumi Wiralodra Indramayu di Kecamatan Losarang. Penelitian ini dilakukan pada SPBE PD. Bumi Wiralodra Indramayu dan SPBE PT. Fajar Cahaya Pantura.

\section{Analisis Data \\ Gambaran Status Gizi}

Tabel 1. Distribusi Frekuensi Responden Berdasarkan Status Gizi

\begin{tabular}{llll}
\hline No. & Status Gizi & Jumlah & Persent \\
\hline 1. & Tidak Normal & 7 & $17,9 \%$ \\
2. & Normal & 32 & $82,1 \%$ \\
\hline & Total & 39 & $100 \%$ \\
\hline
\end{tabular}

Berdasarkan tabel 1. diatas, dapat dilihat bahwa dari 39 responden sebesar 7 responden $(17,9 \%)$ memiliki status gizi tidak normal dan 32 responden $(82,1 \%)$ memiliki status gizi normal.

\section{Gambaran Kelelahan Kerja}

Tabel 2. Distribusi Frekuensi Responden Berdasarkan Kelelahan Kerja

\begin{tabular}{llll}
\hline No. & Kelelahan Kerja & Jumlah & Persent \\
\hline 1. & Rendah & 25 & $64,1 \%$ \\
2. & Tinggi & 14 & $35,9 \%$ \\
\hline & Total & 39 & $100 \%$ \\
\hline
\end{tabular}

Berdasarkan tabel 2 diatas, dapat dilihat bahwa dari 39 responden sebesar 25 responden $(64,1 \%)$ mengalami kelelahan rendah dan 14 responden $(35,9 \%)$ mengalami kelelahan tinggi. 


\section{Hubungan Status Gizi dengan Kelelahan Kerja}

Tabel 3. Hubungan antara Status Gizi dengan Kelelahan Kerja

\begin{tabular}{|c|c|c|c|c|c|c|c|c|c|}
\hline \multirow[t]{3}{*}{ No. } & \multirow{3}{*}{$\begin{array}{c}\text { Status } \\
\text { Gizi }\end{array}$} & \multirow{2}{*}{\multicolumn{2}{|c|}{ Kelelahan Kerja }} & \multirow{3}{*}{ Jumlah } & \multirow{3}{*}{$\begin{array}{c}\text { P- } \\
\text { Value }\end{array}$} & \multirow{3}{*}{$\mathbf{R R}$} & \multirow{3}{*}{ SC } & \multirow{2}{*}{\multicolumn{2}{|c|}{$\begin{array}{c}95 \% \\
\text { Convidene } \\
\text { Interval (CI) }\end{array}$}} \\
\hline & & & & & & & & & \\
\hline & & Rendah & Tinggi & & & & & Lower & Upper \\
\hline & Tidak & $1(2,6 \%)$ & $6(15,4 \%)$ & $7(7,9 \%)$ & & & & & \\
\hline & Normal & & & & & & & & \\
\hline & Normal & $4(61,5 \%)$ & $8(20,5 \%)$ & $32(82,1 \%)$ & 0005 & 3420 & 0486 & 1751 & 6714 \\
\hline & Jumlah & $\begin{array}{c}25(64,1 \\
\%)\end{array}$ & $14(35,9 \%)$ & $39(100 \%)$ & 0,005 & 3,429 & 0,486 & $1, / 51$ & $6, / 14$ \\
\hline
\end{tabular}

Berdasarkan tabel 3. diatas diketahui bahwa dari 7 pekerja yang mempunyai status gizi tidak normal, pekerjanya mengalami kelelahan rendah sebanyak 1 orang $(2,6 \%)$, yang mengalami kelelahan tinggi sebanyak 6 orang $(15,4 \%)$. Dari 32 pekerja yang mempunyai status gizi normal, pekerja yang mengalami kelelahan rendah sebanyak 24 orang $(61,5 \%)$ dan yang mengalami kelelahan tinggi sebanyak 8 orang $(20,5 \%)$. Dari hasil diperoleh nilai ekpetasi $<5$, sehinga uji statistik menggunakan uji Fisher's Exact Test, diperoleh nilai probabilitas ( $\mathrm{P}$-value) sebesar 0,005 karena nilai $P$-value $<0,05$ sehingga dapat disimpulkan bahwa ada hubungan antara status gizi dengan kelelahan kerja pada pekerja bagian operator loading di SPBE Indramayu Tahun 2017.

Untuk mengetahui tingkat kekuatan hubungan dapat dilihat dari nilai Spearman Correlation (SC), dari dua variabel yaitu status gizi dengan kelelahan kerja, berdasarkan hasil perhitungan dengan uji statistic Spearman Correlation dengan menggunakan SPSS versi 16.0 di laboraturium komputer Universitas Wiralodra Indramayu menunjukan nilai $S C=$ 0,486 atau 48,6 \% dengan demikian dapat disimpulkan bahwa terdapat hubungan cukup kuat antara status gizi dengan kelelahan kerja.

\section{Pembahasan}

Status Gizi

Dalam melakukan pekerjaan tubuh memerlukan energi, apabila kekurangan baik secara kualitatif maupun kuantitatif kapasitas kerja akan terganggu. Selain jumlah kalori yang tepat, penyebaran persediaan kalori selama masa bekerja adalah sangat penting. ${ }^{9}$

Penelitian ini dilakukan kepada 39 pekerja SPBE Indramayu untuk mengetahui status gizi para responden. Berdasarkan hasil penelitian, dapat dilihat bahwa dari 39 responden sebesar 7 responden $(17,9 \%)$ memiliki status gizi tidak normal dan 32 responden $(82,1 \%)$ memiliki status gizi normal.

Status gizi pekerja dapat diukur dengan IMT, dengan pengukuran berat badan dan tinggi badan dan dimasukan kedalam rumus $\mathrm{BB}(\mathrm{Kg}) / \mathrm{TB}^{2}(\mathrm{~m})$ dimana hasil pengukuran dibandingkan dengan standar yang ditetapkan Departemen Kesehatan RI.

\section{Kelelahan Kerja}

Kelelahan didefinisikan sebagai suatu pola yang timbul pada suatu keadaan yang secara umum terjadi pada setiap individu yang telah tidak sanggup lagi untuk melakukan aktivitasnya. ${ }^{8}$ Pada penelitian ini, kelelahan kerja diukur menggunakan Subjective Self Rating Test dari Industrial Fatigue Research Committee (IFRC) Jepang, merupakan salah satu kuesioner yang dapat mengukur tingkat kelelahan subjektif. Kuesioner tersebut berisi 30 daftar pertanyaan, sepuluh pertanyaan pertama mengindikasikan adanya pelemahan kegiatan, sepuluh pertanyaan kedua pelemahan motivasi kerja dan sepuluh pertanyaan ketiga mengindikasikan kelelahan fisik. 
Penelitian ini dilakukan kepada 39 pekerja SPBE Indramayu untuk mengetahui kejadian kelelahan kerja. Berdasarkan hasil penelitian dapat dilihat bahwa dari 39 responden sebesar 25 responden $(64,1 \%)$ mengalami kelelahan rendah dan 14 responden $(35,9 \%)$ mengalami kelelahan tinggi.

Adapun upaya-upaya untuk mengurangi kelelahan yaitu dengan menyediakan konsumsi makanan yang mengandung kalori secukupnya sebagai masukan untuk tubuh, bekerja menggunakan metode kerja yang baik, misalnya bekerja dengan menggunakan prinsip efisien gerakan, serta memperhatikan waktu kerja yang teratur, berarti harus dilakukan pengaturan terhadap jam kerja, waktu istirahat dan sarananya, serta masa libur dan rekreasi.

\section{Hubungan Status Gizi dengan kelelahan Kerja}

Dari hasil, diperoleh nilai probabilitas (Pvalue) sebesar 0,005 karena nilai $P$-value $<0,05$ sehingga dapat disimpulkan bahwa ada hubungan antara status gizi dengan kelelahan kerja pada pekerja bagian operator loading di SPBE Indramayu Tahun 2017.

Hal ini sejalan dengan penelitian yang dilakukan oleh Pranoto (2014) mengenai Hubungan status gizi dengan kelelahan kerja pada tenaga kerja bagian weaving di PT. Iskandar Indah Printing Textile Surakarta terdapat hubungan status gizi dengan kelelahan kerja, nilai $p$ value $=0,000 .{ }^{10}$ Dan penelitian yang dilakukan oleh Adi (2013) menunjukkan adanya hubungan yang signifikan antara asupan gizi sebelum bekerja dengan tingkat kelelahan pada pekerja shift pagi bagian packing PT. X Kabupaten Kendal dengan nilai $P=0,0001 .{ }^{11}$ Serta penelitian yang dilakukan oleh Paulina (2016) menyatakan ada hubungan yang bermakna antara status gizi dengan kelelahan kerja pekerja di Kalimantan Steel Kabupaten Kubu Raya dengan nilai $p=0,016 .^{12}$

Penelitian diatas menyebutkan bahwa status gizi mempengaruhi kelelahan kerja, status gizi yang tidak normal baik itu kurang ataupun kelebihan dapat menimbulkan kerugian. Masalah kekurangan atau kelebihan gizi pada orang dewasa (usia 18 tahun ke atas) merupakan masalah penting, karena selain mempunyai resiko penyakit tertentu, juga dapat mempercepat terjadinya kelelahan dan mempengaruhi produktivitas kerja.

Berbeda dengan penelitian yang dilakukan oleh Faiz (2014) tentang Faktor-faktor yang Berhubungan dengan Kelelahan Kerja pada Pekerja Bagian Operator SPBU di Kecamatan Ciputat Tahun 2014. Menunjukkan nilai pvalue $=0,257 \quad(\mathrm{p}$ value $>0,05)$ dapat disimpulkan bahwa tidak ada perbedaan antara IMT pekerja yang mengalami kelelahan dengan pekerja yang tidak mengalami kelelahan. Hal ini dikarenakan mayoritas pekerja memiliki status yang relatif hampir. ${ }^{13}$

\section{Kesimpulan}

Berdasarkan hasil penelitian yang telah dilakukan pada pekerja di SPBE PD. Bumi Wiralodra Indramayu dan SPBE PT. Fajar Cahaya Pantura bagian operator loading Tahun 2017 diperoleh kesimpulan sebagai berikut:

1. Distribusi status gizi pada pekerja bagian operator loading, sebagian besar masuk dalam kategori status gizi normal dengan nilai presentase $82,1 \%$.

2. Distribusi kelelahan kerja pada pekerja bagian operator loading, sebagian besar masuk dalam kategori kelelahan kerja rendah dengan nilai presentase $64,1 \%$.

3. Ada hubungan antara status gizi dengan kelelahan kerja nilai 0,005 (P-value < $0,05)$ pada pekerja bagian operator loading di SPBE Indramayu tahun 2017, terdapat hubungan sedang atau hubungan cukup kuat dengan nilai Spearman Correlation $(\mathrm{SC})=0,485$. 
Saran

Para pekerja sebaiknya mengonsumsi makanan yang bergizi seimbang yang menghasilkan 3500 kalori yang dikonsumsi pada saat sarapan dan makan siang dan jika dijabarkan menurut takaran yaitu nasi/pengganti 4-5 piring, lauk pauk hewani 34 potong, lauk pauk nabati 2-4 potong, sayuran 1,5-2 mangkok dan buah-buahan 2-3 potong dan meminum air putih yang cukup minimal 8 gelas sehari, karena pekerja bagian operator loading merupakan pekerjaan yang mengandalkan kekuatan fisik, selain itu juga pekerja harus memaksimalkan waktu istirahat untuk pemulihan tenaga dan melakukan pekerjaan dengan sikap kerja yang baik sehingga dapat mengurangi beban kerja berlebih.

\section{Daftar Pustaka}

1. Setyawati, L. M. 2007. Promosi Kesehatan dan Keselamatan Kerja, Pelatihan para Medis Seluruh Jawa Tengah, RSU Soeradji Klaten

2. Tarwaka, Bakri S. \& Sudiajeng, L. 2004. Ergonomi untuk Kesehatan, Keselamatan Kerja \& Produktifitas. Surakarta : Uniba Press.

3. Soedirman dan Suma'mur. 2014. Kesehatan kerja dalam perspektif hiperkes dan keselamatan kerja. Jakarta : Erlangga

4. Kuswana, W. S. 2014. Ergonomi dan k3 kesehatan keselamatan kerja. Bandung : Rosdakarya, 2014

5. Ramdan, I.M, 2013. Higiene Industri. Yogyakarta : Penerbit Bimotry

6. Budiono, Sugeng, A.M dkk. 2003. Bunga Rampai Hiperkes dan KK. Semarang: Badan penerbit UNDIP.

7. Ahmad, G. 2007. Antropometri gizi dan peranannya dalam produktivitas kerja. Diakses : 28 Juni 2017. http://www.fleksing.net/pdf/antropomet ri-gizi2348 sama. ${ }^{11}$

8. Soedirman dan Suma'mur. 2014. Kesehatan kerja dalam perspektif hiperkes dan keselamatan kerja. Jakarta : Erlangga

9. Tarwaka, Bakri S. \& Sudiajeng, L. 2004. Ergonomi untuk Kesehatan, Keselamatan Kerja \& Produktifitas. Surakarta : Uniba Press.

10. Pranoto, Bayu 2014. Hubungan status gizi dengan kelelahan kerja pada tenaga kerja bagian weaving di PT. Iskandar Indah Printing Textile Surakarta. Skripsi Fakultas Ilmu Kesehatan Universitas Muhammadiyah Surakarta.

11. Adi, Dewa Putu Gunasastra Septian 2013. Hubungan antara iklim kerja, asupan gizi sebelum bekerja dan beban kerja terhadap tingkat kelelahan pada pekerja shift pagi bagian packing PT.X Kabupaten Kendal. Jurnal Kesehatan Masyarakat 2013, Vol. 2 No. 2 April 2013

12. Paulina, 2016. Faktor-faktor yang berhubungan dengan kelelahan pada pekerja di PT Kalimantas Steel. Jurnal Vokasi Kesehatan, Vol. 11 No. 2 Juli 2016, hlm. 377-384

13. Faiz, Nuril 2014. Faktor-faktor yang berhubungan dengan kelelahan kerja pada pekerja bagian operator SPBU di kecamatan Ciputat tahun 2014. Skripsi FKIK Universitas Islam Negeri Syarif Hidayatullah Jakarta 